\title{
Kitchen Robots: The Importance and Impact of Technology on People's Quality of Life
}

\author{
Ema Fonseca ${ }^{1}$, Inês Oliveira ${ }^{1}$, Joana Lobo ${ }^{1}$, Tânia Mota ${ }^{1}$, \\ José Martins $^{2,4}$, and Manuel Au-Yong-Oliveira ${ }^{1,3(\bowtie)}$ \\ ${ }^{1}$ Department of Economics, Management, Industrial Engineering and Tourism, \\ University of Aveiro, 3810-193 Aveiro, Portugal \\ \{emafonseca,i.oliveira, joanalobo, taniamota, mao\}@ua.pt \\ ${ }^{2}$ INESC TEC, University of Trás-os-Montes e Alto Douro, Vila Real, Portugal \\ jmartins@utad.pt \\ ${ }^{3}$ GOVCOPP, Aveiro, Portugal \\ ${ }^{4}$ Polytechnic Institute of Bragança - EsACT, Mirandela, Portugal
}

\begin{abstract}
The interest in technology allied to household chores has been growing exponentially. Robots like Bimby have revolutionized the way of cooking, since they perform several functions, which were once done manually. How do users of kitchen robots see this continuous evolution and what is the impact on their routines? What are the main advantages associated with this technology and how do non-users see them? This study is a focus on the variables gender, quality of life and technological evolution, as a way to determine if women and men use kitchen robots on an equal scale, if the potentialities of these machines contribute to real improvements in the lives of their users and if, in a near future, this technology will replace the human element in the preparation of meals. To answer these questions, two methodological approaches were followed: quantitative (via questionnaires) and qualitative (via interviews and a focus group). The first approach allowed us to conclude on the profile of kitchen robots and their impact on people's quality of life. The second approach led us to understand the interest of suppliers, and whether the interest is to help human beings or to replace their role altogether in the kitchen. With this study we conclude that kitchen robots have effectively brought improvements in terms of time spent with household tasks, the typical user of this technology is indeed a woman and, finally, that it will be difficult for a robot to replace humans entirely, since anyone who really likes to cook will never stop doing it.
\end{abstract}

Keywords: Innovation - Domestic technologies $\cdot$ Kitchen robots $\cdot$ Gender Technological evolution $\cdot$ Cooking

\section{Introduction}

Nowadays, relationships and interactions are highly dependent on existing technological mechanisms. Even people reluctant to adhere to technological evolution are confronted with it, for example, in a simple phone call. [7] argue that we - humans love to develop electronic gadgets to help us with common tasks. Considering that food and meal preparation are essential and common issues in our routines, this function is increasingly facilitated by small home appliances.

(C) Springer Nature Switzerland AG 2019

Á. Rocha et al. (Eds.): WorldCIST'19 2019, AISC 931, pp. 186-197, 2019.

https://doi.org/10.1007/978-3-030-16184-2_19 
Kitchen robots are just one example of a device created to help prepare meals and these have been gaining importance in Portuguese homes [2]. It is important to state that when a kitchen robot is mentioned, it refers to an equipment that has the autonomy and ability to prepare several pre-programmed meals, according to the information that the user provides, it only being necessary to put the ingredients inside the equipment. Based on this technology, this study aims to discover if this technology has improved quality of life in terms of time spent and resources necessary and if it is used in equal scale by the two genders, or rather whether women are the gender most associated with these domestic tasks [3]. Herein, we intend also to research if the concern of kitchen robot suppliers is to replace the human role in the kitchen on the one hand or, on the other hand, whether the objective is to facilitate the lives of its users. In this context, three research questions were defined:

1. Has the technology associated with cooking (robots) improved the quality of life of families?

2. Are kitchen robots used on an equal scale by both genders?

3. Did robots revolutionize the traditional way of cooking? That is, is the focus of suppliers of this type of technology the development of technology capable of replacing the human in the kitchen, or is the goal just to facilitate the lives of its users?

\section{Kitchen Robots - Literature Review}

This study focuses on a particular home appliance, namely multifunctional kitchen robots, which allow weighing, baking, grinding and even kneading [1]. According to [10] - a Portuguese brand of kitchen robots - this technology should allow the user to only need to program the time, speed and temperature in order to prepare a meal. The most known robot in the world is Bimby or Thermomix, created by Vorwerk. The first robot came to Portugal in 1971, and Vorwerk has been investing and developing new models over the years, always aiming to improve the performance of its robots while working also to increase the number of functionalities available. Like other technological inventions, Bimby is not the only kitchen robot in the market. Several companies around the world have tried to conquer the market with a "copying" strategy, emulating existing machines, creating these few examples of multifunctional devices: Yämmi, Moulinex, Ladymaxx, Philips, KitchenAid, Evolution Mix, Kenwood, MyCook, Bosch, Cooksy, Thermochef Natura, Mamy Gourmet, Monsieur Cuisine and Chef Express. These robots appear in the market at a price considerably lower than that of Bimby, which still remains the most expensive robot in the market (at around 1,000€). Bimby is also the only robot adapted to the latest technological evolution, namely allowing for an Internet connection to thus make possible access to recipes [2], for example.

Focusing attention on home space and on the family, housework is increasingly facilitated by equipment that allows people to have more time to perform other tasks such as to live life more, to its fullest, or simply providing for more time to rest. It is even argued that robots or equipment that have been developed over time, are vital in the execution of domestic tasks, especially for middle-class women, who have their jobs 
throughout the day, and who are always confronted with traditional household chores [3]. [3] also considers that the kitchen is a special space in the sense that it is the place where, especially women, work on the food themselves and, eventually, also to support other people. [4] even argues that the kitchen is designed by men and used by women.

The great advantage attributed to this type of multifunctional kitchen robots is that they can be used by all people. It is an inclusive technological invention, in the sense that it can be used by seniors, by people who do not understand the different cooking times, by single men and/or divorced people who do not know how to cook, by single mothers and even by people seriously concerned about healthy eating. However, [5] argue that men have a different view to that of women in relation to technological objects. Women are more receptive to innovations that help them in some way in social tasks, and men are more affectionate to objects that give them social status. The second comparative advantage of robots is the possibility of preparing diversified meals in a short time: there is "more time to do other things, rather than spending time in the kitchen waiting or even preparing, $[\ldots]$ cooking incredible food at home has never been easier, leading to the ultimate new cooking experience" [2, p. 18]. In addition to diversified meals, it is also possible to prepare healthy foods, which could counter the massive consumption of ready-made food and fast food: "makes for easy and fast preparation of meals and encourages the taking up of healthy eating habits through the use of fresh and raw ingredients at the expense of convenience foods" [1, p. 45]. This author also argues that this type of robots save space, replacing numerous tools that would be necessary to produce each type of meal.

Finally, multifunctional kitchen robots can improve quality of life. However, this concept is very subjective and, in many cases, embracing. According to [8], quality of life can be defined as "the level of satisfaction and comfort that a person or group enjoys", realizing that this will differ from person to person - according to their ideals, tastes and goals. In agreement with [9], quality of life is "the standard of health, comfort, and happiness experienced by an individual or group". For [6, p. 59], quality of life is a more comprehensive term: "[it] is an individual's perception of their position in life in the context of the culture and value systems in which they live and in relation to their goals, expectations, values and concerns, incorporating physical health, psychological state, level of independence, social relations, personal beliefs and their relationship to salient features of the environment - quality of life refers to a subjective evaluation which is embedded in a cultural, social and environmental context" $[12,13]$. In this sense, [3] and [2] argue that robots allow people to save time and resources, and this can be a measurable factor for quality of life. In this study quality of life will be considered as the possibility to save economic resources, to save time and even to improve people's living conditions, in the sense that multifunctional robots perform many tasks that once had to be performed manually. All in all, it is considered that the positive characteristics attributed to this type of robots have impacts in all segments of society. At the industrial level, it allows to cook a meal more efficiently. At the level of the health of users, it is possible to cook a healthy meal in a short period of time. And finally, economically, it allows for savings in the quantity of food used (since the different brands provide a wealth of detailed recipes) and in economic terms, it allows for savings in goods such as gas, electricity and water [1]. However, as with everything else, authors also attribute disadvantages to this type of machine, such as the loss of the 
traditional way of cooking and talent in producing a meal and lessening the contact with the handling of food: "[...] people have less physical contact with food due to technology mediation, they use less perceptive skills to deal with the aesthetics and sensorial elements of cooking practices" [1, p. 49]. Therefore, there is a loss of the need for senses such as touch, taste, and even the talent of conjugating them to produce a good meal.

In order to be able to answer the selected research questions and thus confirm or refute the theories presented in this chapter, the present study will explore the vision and reality of people who use robots and of those who do not, to understand if the literature corresponds to the reality in Portugal.

\section{Methodology}

Before defining the methodology of this study, a SWOT analysis (Table 1) was developed to understand the dynamics of kitchen robots and also to use it as support in the elaboration of the two types of analysis chosen to respond to the proposed research questions.

Table 1. A SWOT analysis of kitchen robots

\begin{tabular}{l|l}
\hline $\begin{array}{l}\text { Strengths } \\
\text { - Product technology }\end{array}$ & $\begin{array}{l}\text { Weaknesses } \\
\text { - High price } \\
\text { - Assistent in the confection } \\
\text { of meals }\end{array}$ \\
- Autonomy of the robot & $\begin{array}{l}\text { Pork with it } \\
\text { - Possible loss of traditional taste }\end{array}$ \\
\hline $\begin{array}{l}\text { Opportunities } \\
\text { - Product not explored by the } \\
\text { market yet }\end{array}$ & $\begin{array}{l}\text { Threats } \\
\text { - Take away/cold meals }\end{array}$ \\
- Innovator product & $\begin{array}{l}\text { There may be other types of robots that replace these } \\
\text { - There is no consumption pattern }\end{array}$ \\
\hline
\end{tabular}

Through the SWOT analysis, it becomes possible to perceive that kitchen robots have the greatest strength in the fact that they are a technological object, an ally in the confection of meals, in the sense that they perform numerous functions independently. Kitchen robots have as opportunities those presented in a vast market defined by the technological evolution, facing such threats as those that competitors offer namely cold meals, and the lack of a pattern of consumption.

The selected methodology intends to ascertain the current impact of kitchen robots on the quality of life of its users and the expectation, about this technology, of those who do not have it. The option of analyzing customers and "non-customers" from a comparative perspective is due to the greater likelihood of obtaining credible and unbiased data on current advantages or potentialities and possible interest in acquiring this product. After the research method was defined a study sample was chosen. In order to gather enough information to answer the research questions, two types of methodological approaches were chosen: a quantitative one - which aims to respond to 
the gender issue (who uses this robots the most?) and the impact on quality of life - and a qualitative one, which aims to respond to the revolution brought to the kitchen and to understand how suppliers see these products and the needs of their consumers; that is, that these products intend to be perceived as facilitators of daily activity, or as an increasingly technological product, capable of replacing the role of the human being.

It is important to note that the quantitative analysis was carried out through two surveys, with the aim of collecting demographic and socioeconomic data, as well as data involving perspectives on the use of this technology. The sample of this survey was composed of 300 respondents, of which 150 have a kitchen robot and 150 do not (the latter do not have any contact with this technology). Both surveys were distributed online, because it is considered that in this way, anonymity is guaranteed, the environmental impact is reduced and there is no influence on the respondent's behaviour. Regarding the age group of the selected sample, the respondents are at least 18 years old, and a maximum age was not stipulated. This choice is based on the fact that until the age of 18 , there is usually still a great dependence on parents, which could lead to a bias in the data if these people answered that they have a kitchen robot, when in fact the users/owners were their parents. Both surveys were launched on October 8, 2018 (Monday) at 10:00 pm, and remained accessible until October 10, 2018 (Wednesday) at 10:00 pm, that is, they were available to receive responses for $48 \mathrm{~h}$. The numerous responses received by women was not a purposeful choice of the group of authors. The questionnaires were distributed randomly on the internet. When the group started to collect responses, we realized that women were in fact the main users of kitchen robots, explaining the percentage of $95 \%$ of women who have the technology. The questionnaires were not delivered to more women than men. Women were the gender, however, which offered to respond, much more so than men.

Both questionnaires (for users and non-users) were distributed online - via the social network Facebook and the communication tool Messenger. The questionnaire of the users of kitchen robots was also made available in two Facebook groups that are frequented, mainly, by people who have the technology and who share experiences, recipes, etc.: "Recipes of Yämmi” (https://www.facebook.com/groups/706607436034 598/) and "Bimby, Without Limits" (https://www.facebook.com/groups/BimbySem Limites/). The group also sent the questionnaire to people who actually owned a robot, since before being shared, those interested in responding were questioned about whether or not they possess this technology.

The qualitative analysis was based on a focus group and two semi-structured interviews with clients, professional users and a robot supplier. The focus group was held on October 12, 2018, at 6:00 pm, in Porto, and lasted approximately for one hour. This action brought together in the same room four people who use kitchen robots to develop much of their work online (bloggers or digital influencers) or in their own homes: Dulce Salvador (client), Teresa Abreu (Healthy Bites blog, nominated for blogs of the year 2018 in the category of "Culinary"), Rui Ribeiro (Faz e Come blog) and a representative of the commercial department of a brand of kitchen robots: Patrícia Cayolla (Yämmi: leading market brand in Portugal) - Table 2. This action aimed to get experts on this technology to talk about the importance of these robots and also to complete with the perspective of a company, to see if what is really offered in the market is what the customer seeks most. 
Table 2. Profile of the participants in the focus group

\begin{tabular}{l|l|l|l}
\hline & Gender & Profession & Age \\
\hline Dulce Salvador & Female & $\begin{array}{l}\text { Senior Technician Communication and Image }- \\
\text { client of kitchen robots }\end{array}$ & 39 years \\
\hline Teresa Abreu & Female & Naval Officer - Healthy Bites blog & 34 years \\
\hline Rui Ribeiro & Male & Trainer - Faz e Come blog & 35 years \\
\hline Patrícia Cayolla & Female & $\begin{array}{l}\text { Commercial Department - Yämmi - a brand of } \\
\text { kitchen robots }\end{array}$ & 45 years \\
\hline
\end{tabular}

The two interviews were held on October 11 and on October 14 (2018), to reinforce the results of the focus group, but with the difference being that they were non face-toface (and, rather, done at a distance) due to the impossibility of traveling and scheduling by the interviewees. This activity was also developed with a client and a digital influencer: Mariana Teixeira (client) and Sílvia Martins (Bocadinhos de Açúcar blog) - Table 3.

Table 3. Profile of the interviewees

\begin{tabular}{l|l|l|l}
\hline & Gender & Profession & Age \\
\hline Mariana Teixeira & Female & Housewife & 47 years \\
\hline Sílvia Martins & Female & Pharmaceutical and Bocadinhos de Açúcar blog & 40 years \\
\hline
\end{tabular}

The methodology chosen did present some challenges, but it was important to gather all the information necessary for the subsequent analysis of the results.

\section{Discussion of the Field Work}

\subsection{Quantitative Analysis}

A data analysis was performed based on the 300 answers obtained (150 users and 150 non-robot users) in the survey.

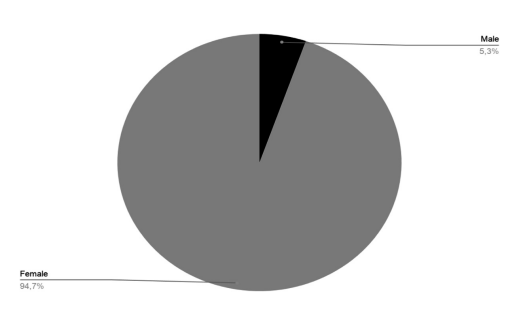

Fig. 1. Users divided by gender

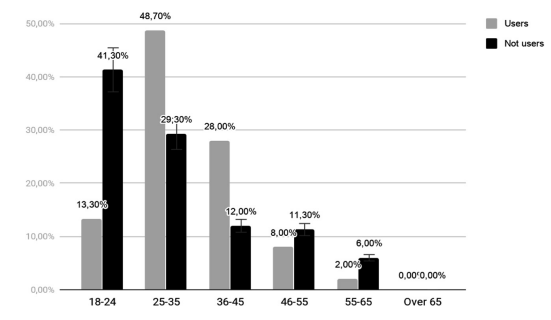

Fig. 2. Age of users and non-users of kitchen robots 
As can be seen in Fig. 1, about 95\% of kitchen robot users are female, corresponding to most of the sample. This result confirms the paradigm initially exposed in the assumptions, that those who use this technology in the kitchen are women. Regarding the age range, Fig. 2 shows that about $49 \%$ of kitchen robot users are between 25 and 35 years of age, followed by $28 \%$ of users between the ages of 36 and 45 years. The age group above 65 years was the one that represented the lowest percentage of users of this technology, which can be justified by the distribution of online surveys, which were not as easy to access. Regarding socio-economic data, 56\% of the users of kitchen robots in our sample have a bachelor's degree or higher, followed by $37 \%$ who have only completed high school. It is also important to note that $47 \%$ of the non-users in our sample also have a bachelor's degree or higher. So, it isn't possible to establish with this study a relationship between literacy and the use of kitchen robots. On the other hand, it can be concluded that it is people aged between 25-35 years and 36-45 years who have the most access to this technology in their homes because they have a more stable life and a higher salary, as well as being more receptive to new technologies. Younger people between 18 and 24 years of age have just entered the labor market and may not have the economic possibilities to acquire this technology yet. From the non-users' perspective, this same fact can be verified, since $41.3 \%$ of the people surveyed correspond to young people aged between 18 and 24 years. Concerning marital status, it was verified that the majority of people who use kitchen robots in their home are married or are living together in a union, reaching a percentage of about $75 \%$, followed by $21 \%$ who are single. Therefore, it was noticed that people who do not live alone are those who use the kitchen robot more, and this can be explained by the fact that they have to cook in greater quantity, which sometimes makes the task of preparing meals more difficult.

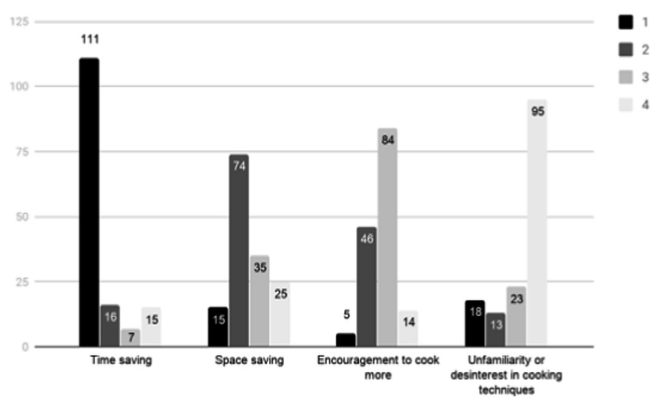

Fig. 3. Advantages of owning a kitchen robot, mentioned by users.

Robot users were asked to order from 1 to 4 (with 1 being the most important and 4 being the least) the advantages of owning such a device - Fig. 3. The main advantage attributed by the people surveyed was the possibility of saving time. The advantage pointed as the second most important is the saving of space, because the robot allows the replacement of several small appliances such as choppers and crushers. There were 
other advantages, such as the incentive to cook more often and the fact that it doesn't require much cooking practice or knowledge to prepare meals. Regarding the time that the robot saves in preparation, it is perceptible that $40 \%$ of the users in the sample believe that this technology allows to save between 1 to $3 \mathrm{~h}$ weekly. About $29 \%$ of the people surveyed consider that they save between 3 to $5 \mathrm{~h}$ a week and about $7 \%$ believe that they save more than $7 \mathrm{~h}$ a week. This shows that about $40 \%$ save, by using the robot every day of the week, between 8 and a half and $25 \mathrm{~min}$ a day in the preparation of their meals. For $7 \%$ of the users who consider that they save more than $7 \mathrm{~h}$ a week, it can be said that they save more than $1 \mathrm{~h}$ a day. It was possible to note that the meal for which users most use the robot is for soups, with a percentage of $45 \%$, followed by $21 \%$ of the users who use it for steaming, and $16 \%$ to make desserts. Only $12 \%$ use this technology to cook side dishes and entrees. So, the most prepared meal by kitchen robots is soup, possibly because it is the meal that implies fewer procedures and, consequently, the one that allows to save more time.

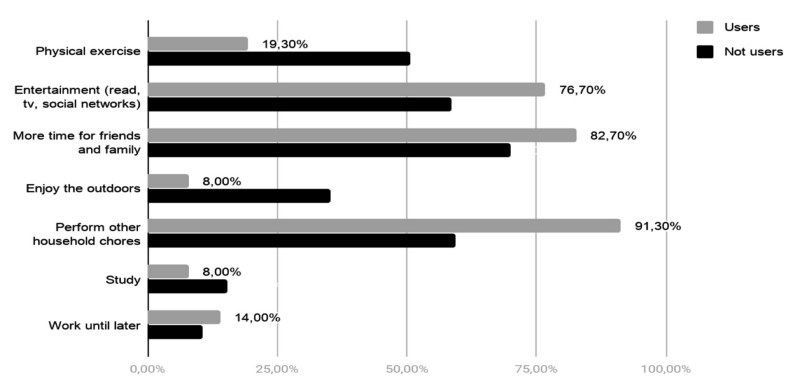

Fig. 4. Use of the time saved by the kitchen robot to dedicate themselves to these activities (by the users and non-users alike, considering they had this technology)

The question posed and visualized in Fig. 4 was one of the most important ones for this study, because it allowed us to associate the use of the robot with quality of life. It is important to mention that they were asked to choose three options about what they do or intend to do while the robot prepares meals. Therefore, when confronted with the question "use this free time for which of the following activities?", about 91\% answered "perform other household chores", $83 \%$ answered "more time for friends and family" and 77\% answered "entertainment". The activities that users accomplish less in the time they save are: "enjoying the outdoors", "studying", "physical exercise" and "work until later". This means that the kitchen robot allows them to save time that is mostly used to perform other tasks at home, but also to enjoy their time with family and friends and for their entertainment, which denotes an improvement in the quality of people's lives. In fact, $98 \%$ of the people surveyed considered that that happened. Regarding the 150 non-users, the same question was asked so that people could reflect on the advantages of having a robot. $70 \%$ felt that they would really benefit to spend more time with friends and family and $59.3 \%$ would do other tasks. It is noticeable that both agree with the main improvements in their routine. 
The non-users have shown either that the main reason for not purchasing a kitchen robot is that they are not interested and do not feel it is a necessity, followed by no financial resources. Another important indicator for assessing quality of life is related to people's beliefs. $69 \%$ of the people who use this technology in their kitchen believe that it is more sustainable and that they have reduced food waste, which is beneficial at the ecological level. $17 \%$ of the respondents still think that the robot has a greater impact on gas savings because they do not have the need to use the stove so often.

\subsection{Qualitative Analysis}

In the qualitative analysis performed, the main ideas drawn up mention that kitchen robots should serve to facilitate the work of their users, be intuitive and easy to use, provide support in recipes that are difficult to produce and make the flavor come near to that of traditional cooking. In the brand's representative perspective (focus group participant), when users think about kitchen robots they associate them to trust, security, ease of use and good after-sales support service, so they should be seen as a complement to the client's life. Saving time and the fact that they could avoid other small appliances were also some of the advantages mentioned in the discussion. When questioned about the paradigm men versus women, participants were unanimous and responded that this technology is - and will continue to be - more used by women than by men, because women are the gender that spend more time on similar tasks (for example: shopping for cooking). They added in fact that man can even cook more often and be a bigger help to women, but society will not feel the change in reality, since it will not be the robot which puts the man in the kitchen, but the situation that leads him to need it, such as in the cases of living alone or enjoying the topic. This is confirmed by Fig. 2 relating to the quantitative analysis, where in a sample of 150 people, about $95 \%$ correspond to women. In terms of the potentialities of this technology, the interviewees mentioned that the technology allows to facilitate the routine in the kitchen (such as cutting, crushing, kneading and weighing), which is the most valued aspect. When considering a future perspective, the idea was common that those who like to cook will not want to be replaced by a robot, that is, the passivity of the user will only exist if there is not an interest in cooking. The kitchen is increasingly seen, according to the participants, as a time to escape the stress of everyday life, a therapy for those who like to spend time cooking. Meal confection requires creativity and the sharing with family or friends and this is not something that they can find in technology. Everyone has assumed that they are aware robots will effectively begin to possess many potentialities that never have been imagined before, but the human factor will always play a dominant role in the kitchen. Thus, the interest is not in having an independent robot, but rather in having a facilitator, since the most important thing is the active participation in the kitchen, both for those who like it or for those who want to learn. In Table 4 it is possible to see some of the main and synthesized ideas of the focus group and interviews. 
Table 4. Main ideas of the focus group and interviews

\begin{tabular}{l|l|l}
\hline & Focus group & Interviews \\
\hline $\begin{array}{l}\text { Technology } \\
\text { advantages }\end{array}$ & $\begin{array}{l}\text { Creation of digital communities for } \\
\text { recipe sharing; preparing meals that } \\
\text { were not prepared before the purchase } \\
\text { or helping with a baby/children }\end{array}$ & $\begin{array}{l}\text { Makes cooking easier while saving } \\
\text { time }\end{array}$ \\
\hline $\begin{array}{l}\text { Buying } \\
\text { decision }\end{array}$ & $\begin{array}{l}\text { Weighted decision between the high } \\
\text { cost of investment and the real need } \\
\text { felt }\end{array}$ & $\begin{array}{l}\text { Assessment of the advantages and } \\
\text { disadvantages, without regret after the } \\
\text { purchase }\end{array}$ \\
\hline $\begin{array}{l}\text { Males vs. } \\
\text { females }\end{array}$ & $\begin{array}{l}\text { Will always be more used by women } \\
\text { than by men, because this is the reality } \\
\text { associated with the tasks in the kitchen }\end{array}$ & $\begin{array}{l}\text { It is an asset to both genders and men } \\
\text { may feel more curious, but they will } \\
\text { not play the prime role in the kitchen }\end{array}$ \\
\hline $\begin{array}{l}\text { Future } \\
\text { perspective }\end{array}$ & $\begin{array}{l}\text { There will actually be a technological } \\
\text { evolution, but humans will never be a a } \\
\text { passive agent; the passion for cooking } \\
\text { is growing, it is seen as an escape from } \\
\text { the routine }\end{array}$ & $\begin{array}{l}\text { Kitchen robots will evolve in their } \\
\text { functions, but creativity will be the } \\
\text { connecting point with humans; the } \\
\text { robot should be a facilitator }\end{array}$ \\
\hline
\end{tabular}

\section{Conclusions and Suggestions for Future Research}

Nowadays people face innumerous tasks, associated with time management and high levels of stress. Therefore, there is a growing interest in technological gadgets that facilitate everyday activities. A simple meal is a necessity for which technology proves to be a powerful ally, in terms of time spent and simplification of the task.

In this article the main interest was to perceive the effective impact of kitchen robots on people's daily lives (starting with the task of producing a meal) and their extension to improved quality of life. Thus, in relation to the first proposed research question: "Has kitchen technology (robots) improved the quality life of families?", it was possible to perceive, by way of the quantitative analysis, that kitchen robots effectively brought improvements in terms of time spent with household tasks and with space that was occupied by other home appliances. As mentioned above, the concept of quality of life is associated with the level of satisfaction and comfort of people, and according to our study, our results show that robots can allow people to perform other domestic tasks or to simply spend more time together, since there is a real saving of time. Thus, as [3] and [2] argue, saving time and space may indeed be the major advantages of this technology. Our study also confirms that kitchen robots have improved quality of life from both an environmental and economic point of view. A small part of the sample admitted that they have started saving more gas and food, in line with the statements of [1]. It is also important to note the health issue. Most of the users surveyed use the robots to make soups and stews, which are healthy meals that can counteract the consumption of fast food and ready meals sold in big shopping malls. Considering the second research question "Are kitchen robots used in equal scale by both genders?", the bibliography used in the theoretical framework associates the use of household gadgets to women and, in our study, it is possible to confirm this with the survey, the focus group and the interviews, that it is in fact women who most 
use kitchen robots. We recall also that in a sample of 150 users, $95 \%$ were female. We also conclude that the typical user of this technology is a woman, who is married or living with a companion, between the ages of 25 and 35 years. Regarding the third (and fourth) research questions "Have robots revolutionized the traditional way of cooking? Should the focus of suppliers of this type of technology be the development of technology capable of replacing human beings, or rather should the focus be to facilitate the lives of its users?", the answers from the focus group and interviews are illustrative. Robots revolutionized the traditional way of cooking in the sense that they proved to be an ally when making a simple meal. All participants in the qualitative analysis agreed that it will be difficult for a robot to replace human beings, since anyone who really likes to cook will never stop doing it. [11] also provided arguments along the same line of thought of our research. The robot will inevitably evolve, but the main interest is to facilitate people's lives. Here it is also important to emphasize the strategies of the brands which sell kitchen robots studied herein, and we conclude that what is offered in the market is what the customer seeks most. Suppliers may have to improve (if the robots are too complex then seniors, for example, may not use them) or maintain their technology (if it is at an appropriate level), since the public of this technology seeks a "friend" and a support to facilitate the production of fast meals and spare the use of more utensils. Although technological evolution is a great opportunity for companies that want to stand out against their competitors, in this market, it is still necessary to evaluate the potential failures of others to understand where they can compensate recent users and captivate potential customers.

Since it is not possible to present in this article all the information collected in the questionnaires, focus group and interviews, due to the limitation of pages and time, it is important to mention that only a small part of the graphics which we possess have been used in the article. If there was more space, the study would reinforce variables such as the cost of kitchen robots, the importance of the price-quality ratio, the most important functionalities and possibilities (cut, grind, knead, digital weighing and balancing or the possibility to see step-by-step recipes) and the sense of fairness/injustice felt in the price paid for the robot - which is knowledge present in the data collected in the questionnaires. As suggestions for future studies, it would be interesting to explore the same variables in a country where women do not assume such a predominant role in the kitchen, as for example in northern Europe. A study in another country would also be interesting to see how people view the type of robots studied herein. It would be interesting to also analyze senior citizens, to understand if this group of people are averse to technology or if they see it as an ally.

\section{Compliance with Ethical Standards}

The present study would not have been possible without the intervention of all those involved. Therefore, we would like to thank the participants we surveyed, as well as the interviewees and the participants in the focus group, for volunteering their time to help us and for sharing some of their important knowledge with us. 


\section{References}

1. Truninger, M.: Cooking with Bimby in a moment of recruitment: exploring conventions and practice perspectives. J. Consum. Cult. 11, 37 (2011)

2. Reffóios, A.: Bimby, The Game Changing Innovative Technology. University Católica Portuguesa (2018)

3. Treusch, P.: Robotic companionship, the making of anthropomatic kitchen robots. Linköping Studies in Arts and Science, number 649, Linköping (2015)

4. Søraa, R.: Mechanical genders, how do humans gender robots? Genderm Technol. Dev. 21(1-2), 99-115 (2017)

5. Badaloni, S., Perini, L.: The Influence of the Gender Dimension in Human-Robot Interaction. University of Padova (2017)

6. Susniene, D., Jurkauskas, A.: The Concepts of Quality of Life and Happiness - Correlation and Differences. Kaunas University of Technology, Panevezys Institute (2009)

7. Rusu, R., Gerkey, B., Beetz, M.: Robots in the kitchen: exploiting ubiquitous sensing and actuation. Robot. Auton. Syst. 56, 844 (2008)

8. Dictionary of Cambridge. https://dictionary.cambridge.org/dictionary/english/quality-of-life. Accessed 16 Oct 2018

9. English Oxford Living Dictionaries. https://en.oxforddictionaries.co/definition/quality_of_ life. Accessed 16 Oct 2018

10. Official Website of Yämmi. https://www.yammi.pt. Accessed 16 Oct 2018

11. Yamazaki, T.: Beyond the smart home. In: 2006 International Conference on Hybrid Information Technology, vol. 2, pp. 350-355 (2006)

12. Au-Yong-Oliveira, M., Gonçalves, R., Martins, J., Branco, F.: The social impact of technology on millennials and consequences for higher education and leadership. Telemat. Inform. 35, 954-963 (2018)

13. Gonçalves, R., Martins, J., Rocha, Á.: Internet e redes sociais como instrumentos potenciadores de negócio. RISTI-Revista Ibérica de Sistemas e Tecnologias de Informação 09-11 (2016) 